\title{
Analysis of Data Provided by User/Third Party
}

National Cancer Institute

\section{Source}

National Cancer Institute. Analysis of Data Provided by User/Third Party. NCI Thesaurus.

Code C139458.

The investigation involved the analysis of relevant data provided by the user (e.g.

healthcare professional, patient, clinical engineer) or a third party (e.g. testing facility) in view of supporting the identification of possible causes for the adverse event. 